\title{
Association between regular arrangement of collecting venules and Helicobacter pylori status in routine endoscopy
}

\author{
Cong Yuan ${ }^{1+}{ }^{0}$, Xue-Mei Lin ${ }^{2,3 \dagger}$, Yan Ou ${ }^{4}$, Lin Cai ${ }^{4}$, Qian Cheng ${ }^{4}$, Ping Zhou ${ }^{5}$ and Juan Liao ${ }^{4,6^{*}}$ (i)
}

\begin{abstract}
Background: The sensitivity of regular arrangement of collecting venules (RAC)-positive pattern for predicting Helicobacter pylori (H. pylori)-negative status greatly altered from 93.8 to $48.0 \%$ in recent two decades of various studies, while the reason behind it remained obscure. The aim of this study was to investigate the value of RAC as an endoscopic feature for judging $H$. pylori status in routine endoscopy and reviewed the underlying mechanism.

Methods: A prospective study with high-definition non-magnifying endoscopy was performed. RAC-positive and RAC-negative patients were classified according to the collecting venules morphology of the lesser curvature in gastric corpus. Gastric biopsy specimens were obtained from the lesser and greater curvature of corpus with normal RAC-positive or abnormal RAC-negative mucosal patterns. Helicobacter pylori status was established by hematoxylin and eosin staining and immunohistochemistry.

Results: 41 RAC-positive and 124 RAC-negative patients were enrolled from June 2020 to September 2020. The prevalence of $\mathrm{H}$. pylori infection in patients with RAC-positive pattern and RAC-negative pattern was 7.3\% (3/41) and 71.0\% (88/124), respectively. Among all 124 RAC-negative patients, 36 (29.0\%) patients were H. pylori-negative status. Ten patients (32.3\%) demonstrated RAC-positive pattern in 31 H. pylori-eradicated cases. The sensitivity, specificity, positive predictive value, and negative predictive value of RAC-positive pattern for predicting $\mathrm{H}$. pylori-negative status were $51.4 \%$ (95\% Cl, 0.395-0.630), 96.7\% (95\% Cl, 0.900-0.991), 92.7\% (95\% Cl, 0.790-0.981), and $71.0 \%(95 \% \mathrm{Cl}$, 0.620-0.786), respectively.
\end{abstract}

Conclusions: RAC presence can accurately rule out $H$. pylori infection of gastric corpus, and H. pylori-positive status cannot be predicted only by RAC absence in routine endoscopy.

Trial registration The present study is a non-interventional trial.

Keywords: Helicobacter pylori, Gastrointestinal endoscopy, Gastric mucosa, Digestive system diagnostic techniques

\section{Background}

Helicobacter pylori (H. pylori) infection has been involved in over $60 \%$ of people in the world [1], which is a wellknown risk factor for gastric disorders including active

\footnotetext{
*Correspondence: juanliao@scu.edu.cn

${ }^{\dagger}$ Cong Yuan and Xue-Mei Lin contributed equally to this work

${ }^{4}$ Department of Gastroenterology, West China Forth Hospital, West China

School of Public Health, Sichuan University, Chengdu 610041, China

Full list of author information is available at the end of the article
}

gastritis, peptic ulcer, MALT lymphoma and adenocarcinoma [2]. Invasive and noninvasive diagnostic tests for $H$. pylori have been extensively used in the clinical practice [3-5]. Among these methods, endoscopic approach is a potential benefit, which can provide real-time mucosal findings and prompt targeted biopsy. In recent years, the technological developments in magnifying endoscopy have allowed accurate diagnosis of $H$. pylori infection by evaluating the pit and vascular patterns [4]. 
However, magnifying endoscopy is less commonly used in routine clinical practice, and the procedure requires more time and expenditure, and specialized training. Therefore, diagnosis of $H$. pylori by non-magnifying endoscopy would still be of great interest to the general endoscopists.

By using non-magnifying endoscopy, regular arrangement of collecting venules (RAC) in the gastric body is generally recognized as a characteristic feature of a normal stomach without $H$. pylori infection [6]. In 2002, Yagi et al. [6] study had indicated that the presence of RAC at the distal part of the lesser gastric curvature for predicting $H$. pylori-negative normal stomach had more than 90\% sensitivity and specificity. RAC pattern becomes invisible when gastric body mucosa was affected by $H$. pylori infection [7]. However, in numerous subsequent studies between 2004 and 2019, RAC absence was associated with $H$. pylori-positive status in varied proportion from $47.3 \%$ to $94.4 \%$ among different cases [8-17]. Hence, the absence of RAC did not always indicate the positive status of $H$. pylori. So, the aim of our study was to investigate the prevalence of $H$. pylori in daily routine endoscopy without magnification, and evaluate the association between RAC pattern and H. pylori status.

\section{Methods}

\section{Patients collection}

We designed a prospective study including inpatients and outpatients who underwent upper GI endoscopy from June 2020 to September 2020. Consecutive patients with more than 18-years old were invited to attend the study. The following baseline characteristics were collected: age, sex, use of nonsteroidal anti-inflammatory drugs (NSAIDs), and history of $H$. pylori eradication in the last one year. Patients were excluded if they had previous partial gastrectomy, the diseases such as cirrhosis, chronic respiratory disorders, inflammatory bowel disease, collagen disease, and taken regular use of anticoagulants. The study protocol was approved by the institutional review board of West China Forth Hospital, Sichuan University (No. HXSY-EC-2020064). All participating patients gave written informed consent.

\section{RAC pattern classification of corpus by non-magnifying endoscopy}

After routine examination of the whole stomach by high-resolution endoscopy (GIF-H290; Olympus Optical Co. Ltd., Tokyo, Japan), the close-up observation of corpus was performed with a distance no more than $10 \mathrm{~mm}$ between the endoscope tip and mucosal surface, as described previously [13]. The collecting venules (CVs) morphology at the lesser gastric curvature was classified [18]: regular arrangement of CVs as RAC-positive pattern (Fig. 1a), obscure and irregular arrangement of $\mathrm{CVs}$ as RAC-negative pattern. Some researchers further divided RAC-negative corpus mucosa into several types $[3,13-15,19]$, such as spotty redness, diffuse redness, mosaic pattern, cleft-like appearance, untypical pattern, et al. (Fig. 1b-f).

\section{Biopsy specimens in the corpus and diagnosis of $H$. pylori infection}

H. pylori infection in some patients only affected gastric antrum [6], and RAC appeared only in gastric body and fundus [7]. To ensure that $H$. pylori has infected the body of stomach, and explore the relationship between RAC pattern and corpus H. pylori status, two biopsy specimens were taken directly from the lesser curvature and greater curvature in the corpus, avoiding some certain areas such as erosion, ulceration and gastric mucosa with a suspicion of intestinal metaplasia. These two sites are recommended by the update Sydney System for gastric corpus biopsy [20], and the gastric body greater curvature is a better site to detect current $H$. pylori infections [21].

The muscularis mucosae side of each biopsy specimen was stretched and fixed on filter paper, then bathed in a $10 \%$ formalin solution. $5-\mu \mathrm{m}$ sections of paraffin wax embedded tissues were stained. A diagnosis of $H$. pylori infection was achieved if bacillary and/or coccoid $H$. pylori was identified on histopathological examination with $\mathrm{H} \& \mathrm{E}$ assay and/or monoclonal immunohistochemistry (IHC) (mouse monoclonal antibody, MX014, MXB Biotechnologies, Fuzhou, China). In general, only rodshaped H. pylori can be identified in the H\&E sections considering that coccoid $H$. pylori may mimic other bacteria or cell debris on H\&E preparations [21]. To avoid the interference of impurities in IHC sections, more than 5 spherical $H$. pylori per high power field was identified as coccoid $H$. pylori positive (Fig. 2). All the assessment of gastric specimens was conducted by two pathologists, who were blinded to the clinical and endoscopic findings.

\section{Statistical analysis}

With the assumption that the RAC would have a sensitivity of $90 \%$ with a confidence level of $95 \%$ and precision of $10 \%$, a total of 158 patients were required. Continuous data with normal distribution were presented as mean $\pm \mathrm{SD}$, continuous data without normal distribution were presented as median and interquartile range (IQR) and for nominal variables data were presented as percentages. The normality was tested using the Kolmogorov-Smirnov test. Regarding the association between RAC pattern and H. pylori status, the sensitivity, specificity, positive predictive value 

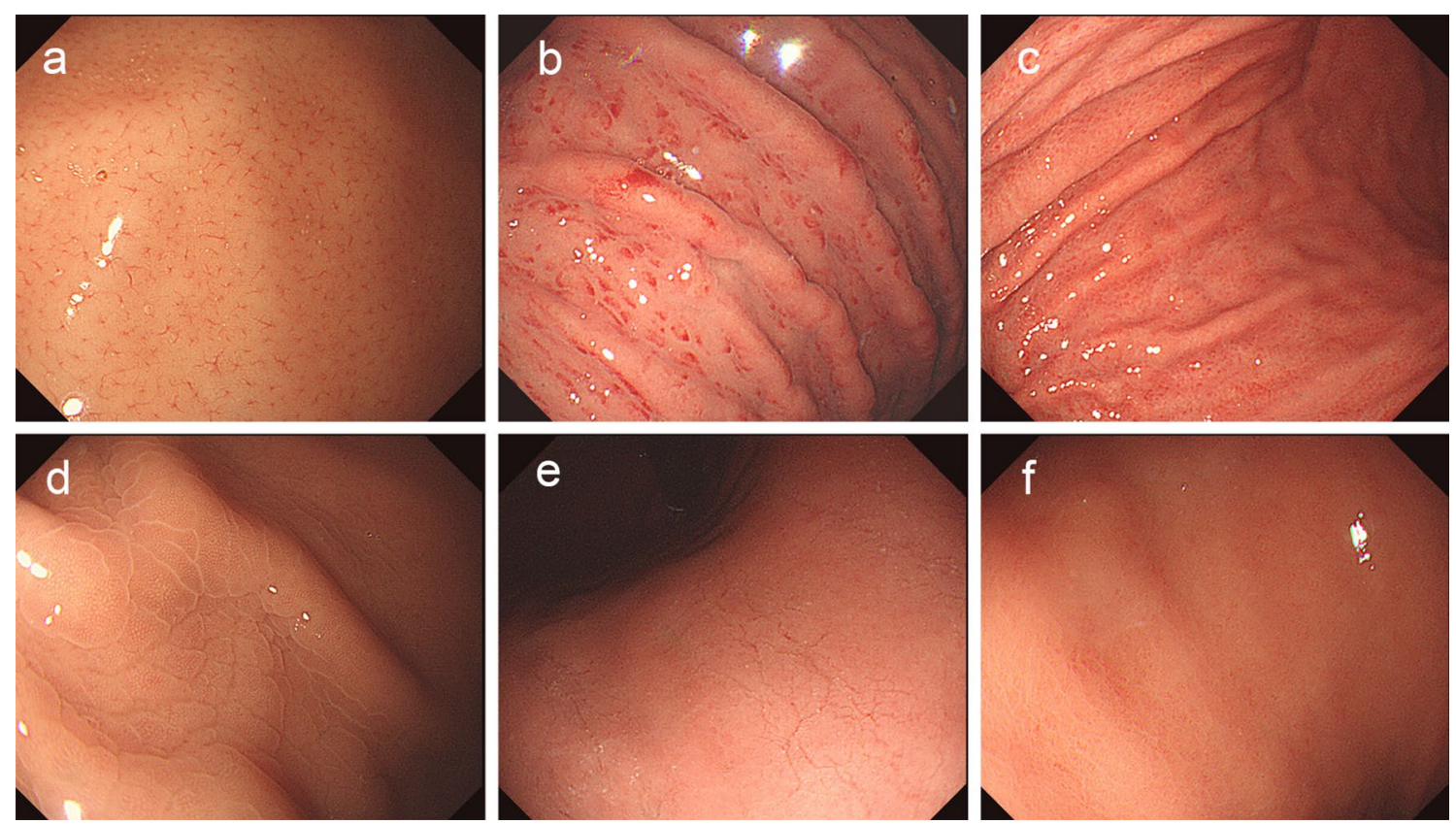

Fig. 1 Normal RAC-positive pattern (a) and abnormal RAC-negative pattern (b-f) in the gastric corpus observed by non-magnifying endoscopy a RAC-positive pattern showing numerous minute red dots with claw-like and regular intervals; $\mathbf{b}$ Spotty redness appearance; $\mathbf{c}$ Diffuse redness appearance; $\mathbf{d}$ Mosaic-like appearance; $\mathbf{e}$ Cleft-like appearance; $\mathbf{f}$ RAC-invisible mucosa showing untypical appearance with difficulties to classify

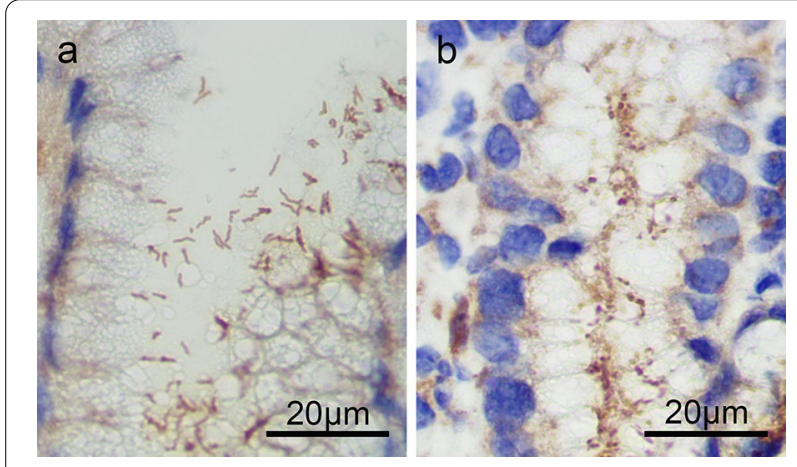

Fig. 2 H. pylori detected by immunohistochemical stain (IHC). a The predominant bacilliform of $H$. pylori can be seen. $\mathbf{b}$ A large amount of coccoid H. pylori is visible. (IHC, $\times 1000$ oil immersion lens)
(PPV), negative predictive value (NPV), and 95\% confidence intervals (CI) were calculated [22]. Chi-square test and Mann-Whitney U-test were used to compare RAC-positive and RAC-negative group. The inter- and intraobserver reproducibility was calculated by using kappa values as described by Landis and Koch [23]. A $P$ value of less than 0.05 was required for significance. All statistical analyses were performed using SPSS statistical software (version 22 SPSS Inc., Chicago, US).

\section{Results}

Study subjects and baseline characteristics

Demographics and endoscopic mucosal patterns were summarized in Table 1. A total of 165 patients were enrolled with a median age of 52 years (IQR 41, 61; range 18-79 years), and 107 (64.8\%) patients were male. The age distribution of RAC-positive and RAC-negative groups was different, and RAC was more common in cases under 50 years old $(P<0.05)$. There was no difference in RAC between NSAIDs user and non-user groups $(P<0.05) .10$ patients $(32.3 \%)$ demonstrated RAC-positive pattern in $31 \mathrm{H}$. pylori-eradicated cases.

\section{H. pylori infection status in RAC-positive and RAC-negative pattern}

H. pylori positive rate was different between RACpositive and RAC-negative group $(7.3 \%$ versus $71.0 \%$, $P<0.05)$. In RAC-positive group, $H$. pylori-negative status was revealed in $92.7 \%(38 / 41)$ patients. In RAC-negative group, $29.0 \%$ (36/124) of patients were $H$. pylori-negative status. Among 88 (71.0\%, 88/124) $H$. pylori-positive patients in RAC-negative group, 80 had both spherical and rod shape, 5 had only spherical shape and 3 had only rod shape. In RAC-negative subgroups, the $H$. pylori positive rate was $80.6 \%, 80.0 \%, 81.6 \%, 52.6 \%$ and $37.5 \%$ for spotty redness, diffuse redness, mosaic pattern, cleft-like 
Table 1 Baseline characteristics of the patients in current study

\begin{tabular}{|c|c|c|c|c|}
\hline Characteristics & Total $(n=165)$ & RAC positive $(n=41)$ & RAC negative $(n=124)$ & $P$ value \\
\hline Age, years (median, IQR) & $52(41,61)$ & $40(30,51)$ & $49(37,58)$ & 0.005 \\
\hline \multicolumn{5}{|l|}{ Age } \\
\hline$<50$ years & $89(53.9)$ & 29 & 60 & \multirow[t]{2}{*}{0.01} \\
\hline$\geq 50$ years & $76(46.1)$ & 12 & 64 & \\
\hline \multicolumn{5}{|l|}{ Sex } \\
\hline Male & $107(64.8)$ & 28 & 79 & \multirow[t]{2}{*}{0.59} \\
\hline Female & $58(35.2)$ & 13 & 45 & \\
\hline \multicolumn{5}{|l|}{ NSAIDs } \\
\hline Yes & $31(18.8)$ & 11 & 20 & \multirow[t]{3}{*}{0.39} \\
\hline No & $100(60.6)$ & 36 & 64 & \\
\hline Unknown & $34(20.6)$ & & & \\
\hline \multicolumn{5}{|l|}{ H. pylori status } \\
\hline Positive & $91(55.2)$ & 3 & 88 & \multirow[t]{2}{*}{$<0.001$} \\
\hline Negative & $74(44.8)$ & 38 & 36 & \\
\hline \multicolumn{5}{|l|}{ H. pylori eradicated } \\
\hline Yes & $31(18.8)$ & 10 & 21 & \multirow[t]{3}{*}{0.48} \\
\hline No & $101(61.2)$ & 26 & 75 & \\
\hline Unknown & $33(20.0)$ & & & \\
\hline
\end{tabular}

IQR interquartile range, NSAIDs nonsteroidal anti-inflammatory drugs, $R A C$ regular arrangement of collecting venules

Table 2 H. pylori infection status in endoscopic mucosal patterns

\begin{tabular}{lrrrr}
\hline Mucosal patterns & Total & \multicolumn{3}{c}{ H. pylori status (n, \%) } \\
\cline { 3 - 5 } & & Negative & Positive & P value \\
\hline RAC positive & 41 & $38(92.7)$ & $3(7.3)$ & $<0.001^{*}$ \\
RAC negative & 124 & $36(29.0)$ & $88(71.0)$ & \\
Spotty redness & 31 & $6(19.4)$ & $25(80.6)$ & \\
Diffuse redness & 20 & $4(20.0)$ & $16(80.0)$ & \\
Mosaic & 38 & $7(18.4)$ & $31(81.6)$ & \\
Cleft & 19 & $9(47.4)$ & $10(52.6)$ & \\
Untypical pattern & 16 & $10(62.5)$ & $6(37.5)$ & \\
\hline
\end{tabular}

RAC regular arrangement of collecting venules. $P<0.001 *$ RAC-positive versus RAC-negative group

appearance, and an untypical pattern, respectively (Table 2). RAC presence at the lesser gastric curvature was associated with a $51.4 \%$ sensitivity (95\% CI, $0.395-$ 0.630 ) and a $96.7 \%$ specificity (95\% CI, 0.900-0.991) for estimating $H$. pylori-negative status. PPV and NPV were 92.7\% (95\% CI, 0.790-0.981) and 71.0\% (95\% CI, 0.620$0.786)$, respectively.

\section{Inter- and intraobserver agreement assessment}

The k-values for inter- and intraobserver agreement for the endoscopic mucosal patterns were significant. The k-values for inter- and intraobserver agreement for the assessment of $H$. pylori status were also significant (Table 3).

\section{Discussion}

RAC presence has been well known as a characteristic endoscopic feature in $H$. pylori-negative normal stomach $[6,7]$. In 2002, Yagi et al. [6] researchers have indicated that the presence of RAC for predicting $H$. pylori-negative normal stomach had $93.8 \%$ sensitivity and $96.2 \%$ specificity. In many subsequent studies (Table 4) [8-17], the RAC-positive pattern also demonstrated a high

Table 3 Inter- and intraobserver agreement

\begin{tabular}{|c|c|c|c|c|}
\hline & \multicolumn{4}{|c|}{ Interobserver agreement } \\
\hline & $\%$ agreement & $\mathrm{k}$ value $(95 \% \mathrm{Cl})$ & $\%$ agreement & $\mathrm{k}$ value $(95 \% \mathrm{Cl})$ \\
\hline RAC pattern & 85.6 & $0.74(0.71-0.78)$ & 89.4 & $0.88(0.78-0.96)$ \\
\hline H. pylori status & 92.7 & $0.86(0.80-0.92)$ & 93.5 & $0.94(0.87-0.98)$ \\
\hline
\end{tabular}

The k-values for inter- and intraobserver agreement for mucosal patterns and $H$. pylori status were significant

$\mathrm{Cl}$ confidence interval 


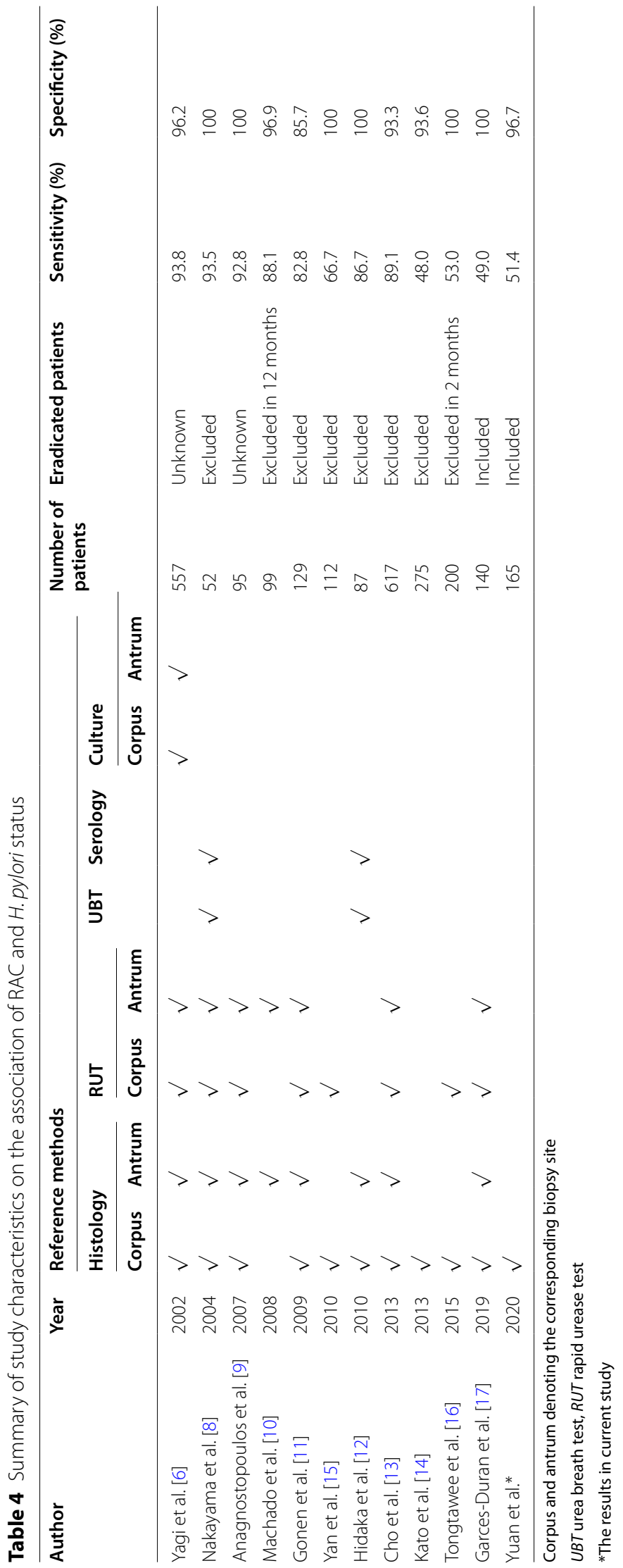


specificity between $85.7 \%$ and $100 \%$, however, the sensitivity of RAC-positive pattern varied from $93.5 \%$ to $48.0 \%$. In our study, RAC presence has only $51.4 \%$ sensitivity and $71.0 \%$ NPV for predicting $H$. pylori-negative status in routine clinical practice despite a good specificity (96.7\%) and PPV (92.7\%). These studies strongly supported the idea that the presence of RAC in the lesser corpus can accurately identify $H$. pylori-negative gastric body mucosa [24], but RAC absence did not always point out $H$. pylori-positive corpus mucosa.

In routine endoscopy, many conditions can cause the disappearance of RAC, including H. pylori-related factors (such as chronic active gastritis caused by current $H$. pylori infection, and chronic inactive gastritis after $H$. pylori eradication), and $H$. pylori-unrelated factors (such as $H$. pylori-negative gastritis, and gastropathy induced by liver cirrhosis, et al.) [6, 25-28]. Shiota et al. [29] and Nordenstedt et al. [30] had found $H$. pylori-negative gastritis in $17.7 \%$ and $21 \%$ of patients with histologic gastritis. Although $H$. pylori-negative gastritis was a condition that cannot be ignored, the diagnosis process was complicated and difficult to apply in daily work $[29,30]$. Thus, we have not further evaluated such patients with H. pylori-negative gastritis in the present study. In inclusion criteria, the patients with liver cirrhosis have been excluded. In addition, NSAIDs were also one of the common causes of gastropathy. Our results revealed that no significant differences in RAC pattern were found in a small group of patients treated with NSAIDs (Table 1), which was consistent with previous studies [17].

In view of the high prevalence of H. Pylori, H. pylorirelated factors are the lead cause of RAC disappearance. RAC absence can be happened in the patients with current or past $H$. Pylori infection [26, 31]. In suspicious patients with chronic active gastritis, in addition to the disappearance of RAC, the accuracy of $H$. pylori status can be further improved by combining with other endoscopic manifestations, such as diffuse redness, spotty redness and swelling of areae gastricae [14]. H. pylorieradicated cases have been arising considering the preventive effect of $H$. pylori eradication therapy for gastric cancer [32]. However, RAC will not reappear immediately after $H$. pylori eradication. Yagi et al. [26] have revealed that the RAC did not recover for over one year in $68 \%$ subjects after successful $H$. pylori eradication. Garces-Duran et al. [17] also found that about half of past H. pylori-eradicated patients were RAC-negative. Thus, RAC would be invisible in a considerable proportion of H. pylori-eradicated patients. We found that RAC was still absent in about two-thirds of patients $(67.7 \%, 21 / 31)$ with $H$. pylori eradication history. These results revealed that RAC absence did not always indicate H. pylori-positive status in patients with $H$. pylori eradication history.
Although detailed medical records were very vital for identifying the eradicated cases, some patients still failed to provide past $H$. pylori eradication clearly. In addition, partially eradicated patients may come from unintended H. pylori sterilization because of the infectious diseases in other organs. Besides, H. pylori may be also naturally eradicated without bactericidal therapy. These conditions made it difficult for us to accurately judge the past infection of $H$. pylori in clinical practice. Therefore, we investigated the total $H$. pylori prevalence in RAC-negative patients, and found that only $71.0 \%(88 / 124)$ subjects were $H$. pylori-positive. $29.0 \%(36 / 124)$ of patients were H. pylori-negative status despite the fact that RAC disappeared, which resulting in the low sensitivity (51.4\%) and NPV (71.0\%).

In these reports (Table 4) [6, 8-17] on the relationship between RAC pattern and $H$. pylori status, the sensitivity of RAC varied greatly from $93.8 \%$ to $48.0 \%$, which may be related to different baseline characteristics of the patients and multiple methods of $H$. pylori status judgment. Among the 11 studies, four studies [9, 11, 13, 17] simultaneously detected $H$. Pylori in gastric body and antrum by histological examination and rapid urease test (RUT), and showed that the sensitivity of RAC decreased from 92.8 to $49.0 \%$ due to the difference in baseline characteristics. For example, in Garces-Duran et al. [17] study the patients with NSAIDs usage and past $H$. pylori eradication were enrolled, and the sensitivity was only $49.0 \%$. In the present study, we did not also exclude analogous patients and the sensitivity was low (51.4\%). Even if the patients with $H$. pylori eradication history were excluded in inclusion criteria, the sensitivity was only $66.7 \%$ in Yan et al. [15] study and $48.0 \%$ in Kato et al. [14] study. Indeed, in clinical work, it is very difficult for us to completely exclude insidious past $H$. pylori infection, especially unintended $\mathrm{H}$. pylori sterilization and spontaneous eradicators mentioned above. Interestingly, the two studies $[14,15]$ only detected $H$. pylori in gastric body by histology and/or RUT. Therefore, the prevalence of $H$. pylori could only reflect the $H$. pylori status in the corpus, which was similar to our study. One studies [10] merely detected H. pylori in the antrum by histology and RUT, which can not reveal the infection of $H$. pylori in gastric body because in some patients the infection only affected gastric antrum [6]. Indeed, it was not appropriate to use the RAC in the body to predict H. pylori status in the antrum in this study.

The corrosion casting and scanning electron microscopy of blood vessels in gastric corpus mucosa revealed that CVs gradually formed at the level of gastric foveolar layer and descend to join the submucosal plexus, without receiving any further capillary tributaries on their course (glandular layer) [33-35]. The CV and the drainage vein 
below showed a tree-like stereostructure [36]. The morphologic changes or destruction of gastric foveola and gastric body glands can affect the arrangement and shape of CVs. In normal gastric body mucosa, the length of gastric foveola is about $200 \mu \mathrm{m}$ or less [37, 38], which is within the penetration depth of the endoscopic illumination light [39]. Therefore, regular arrangement of CVs (RAC) can be seen in normal gastric body mucosa by gastroendoscopy.

RAC absence is one of the main manifestations of chronic active gastritis due to $H$. pylori current infection $[6,7,12]$. The gastric mucosal active inflammation should relieve shortly after eradication of $H$. pylori, however, RAC was still negative in some patients [17, 26]. Mild chronic inflammation in gastric mucosa can persist for more than 5 years after successful $H$. pylori eradication therapy in up to one-fifth of patients [40]. The appearance of RAC was the endoscopic manifestation of normal gastric corpus mucosa without pathologic changes $[41,42]$. Saghier et al. [43] study has showed that foveolar length of corpus mucosa in $H$. pylori gastritis patients was significantly increased than that of normal $H$. pyloriuninfected gastric corpus. In a recent study from our team [38], we found that the prolongation of gastric foveolae could result in the invisibility of RAC. We revealed that in addition to $H$. pylori current infection, chronic inactive gastritis in $H$. pylori-eradicated patients can also cause RAC disappearing through the prolongation of gastric foveolae. Therefore, along with the increase of $H$. pylori-eradicated patients, the subjects with RACnegative and $H$. pylori-negative entity are further accumulating, which can lead to decreased sensitivity. Hence, only RAC disappearance was no longer a reliable feature to judge $H$. pylori-positive status in daily practice. In fact, in Yagi et al. [6] study, the predicting corpus mucosa of RAC presence was not only $H$. pylori-negative status but also normal pathological features. However, in numerous studies [8-17], only H. pylori status was evaluated, ignoring gastric mucosa pathological abnormality, in particular the changes of gastric foveolae length. In a word, RAC presence was the endoscopic manifestation of normal gastric corpus mucosa with normal histology [41, 42], which can not only exclude H. Pylori infection, but also eliminate the pathological abnormalities of corpus mucosa caused by other factors.

Our study had several limitations: Firstly, our study only explored the relationship between RAC and $H$. Pylori infection in gastric corpus mucosa, and $H$. pylori status of gastric antrum mucosa was not evaluated. Therefore, $H$. Pylori status of gastric corpus cannot be represented the entire stomach. Secondly, histological detection of $H$. pylori can reduce the accuracy because of patchy distribution of the bacteria. Combination of multiple methods was helpful to more accurate detection of $H$. Pylori such as urea breath test, serological examination, PCR and culturing. However, PCR and H. pylori culturing was not convenient in daily clinical practice. In addition, urea breath test and serological examination cannot distinguish the patients in which the gastric body was only affected, and not be performed in the present study. Thirdly, RAC accuracy may be affected by patient age [44]. We did not conduct age stratification analysis due to the limited sample size. Lastly, this was a singlecenter study, with a limited number of cases and a short time span. In future, more patients can be included to analyze different detective methods of $H$. pylori and different patient subgroups to strengthen our results.

\section{Conclusions}

The present study has demonstrated that RAC presence can accurately rule out the $H$. pylori infection of gastric corpus, but the positive status of $H$. pylori cannot be effectively predicted only by the absence of RAC in routine endoscopy. In patients with RAC-negative pattern, other endoscopic features such as diffuse redness, spotty redness and swelling of areae gastricae et al. should be combined to improve the diagnosis of $H$. pylori status.

\section{Abbreviations \\ H. pylori: Helicobacter pylori; RAC: Regular arrangement of collecting venules; CVs: Collecting venules; IHC: Immunohistochemistry; IQR: Interquartile range; NSAIDs: Nonsteroidal anti-inflammatory drugs; Cl: Confidence interval; PPV: Positive predictive value; NPV: Negative predictive value; RUT: Rapid urease test; UBT: Urea breath test.}

\section{Acknowledgements}

Not applicable.

\section{Authors' contributions}

$\sqcup J$ designed the study. YC and OY conducted the experiments, analyzed data, and drafted the manuscript. LX and ZP performed the pathological assessment. YC, OY, CL, and $C Q$ were involved in the collection of gastric specimens, data analysis, and reviewed the paper. All authors read and approved the final manuscript.

\section{Funding}

This work was supported by a grant from the International Cooperation Project of Sichuan Science and Technology Department (to Juan Liao, No.2020YFH0106). The funder had no influence on the study design, data collection and analysis, decision to publish, or preparation of the manuscript.

Availability of data and materials

All data analyzed during this study are included in this published article.

\section{Declarations}

\section{Ethics approval and consent to participate}

The study protocol was approved by the Institutional Review Board of West China Forth Hospital, Sichuan University (No. HXSY-EC-2020064). All participating patients gave written informed consent.

Consent to publish

Not applicable. 


\section{Competing interests}

Authors declare no conflicts of interest for this article.

\section{Author details}

${ }^{1}$ Department of Gastroenterology, Affiliated Hospital of North Sichuan Medical College, Nanchong 637000, Sichuan, China. ${ }^{2}$ Department of Pathology, Basic Medical College of North Sichuan Medical College, Nanchong 637000, Sichuan, China. ${ }^{3}$ Department of Pathology, Affiliated Hospital of North Sichuan Medical College, Nanchong 637000, Sichuan, China. ${ }^{4}$ Department of Gastroenterology, West China Forth Hospital, West China School of Public Health, Sichuan University, Chengdu 610041, China. ${ }^{5}$ Department of Pathology, West China Forth Hospital, West China School of Public Health, Sichuan University, Chengdu 610041, China. ${ }^{6}$ Non-communicable Diseases Research Center, West China-PUMC C.C. Chen Institute of Health, Sichuan University, Chengdu 610041, China.

Received: 22 February 2021 Accepted: 8 October 2021 Published online: 20 October 2021

\section{References}

1. Hooi JKY, Lai WY, Ng WK, Suen MMY, Underwood FE, Tanyingoh D, et al. Global prevalence of helicobacter pylori infection: systematic review and meta-analysis. Gastroenterology. 2017;153(2):420-9. https://doi.org/10. 1053/j.gastro.2017.04.022.

2. Chey WD, Wong BC, Practice Parameters Committee of the American College of $\mathrm{G}$. American College of Gastroenterology guideline on the management of Helicobacter pylori infection. Am J Gastroenterol. 2007; 102(8):1808-25. https://doi.org/10.1111/j.1572-0241.2007.01393.x.

3. Glover B, Teare J, Patel N. A systematic review of the role of non-magnified endoscopy for the assessment of $\mathrm{H}$. pylori infection. Endosc Int Open. 2020; 8(2):E105-E14. https://doi.org/10.1055/a-0999-5252.

4. Qi Q, Guo C, Ji R, Li Z, Zuo X, Li Y. Diagnostic performance of magnifying endoscopy for helicobacter pylori infection: a meta-analysis. PLOS ONE. 2016;11(12): e0168201. https://doi.org/10.1371/journal.pone.0168201.

5. Godbole G, Megraud F, Bessede E. Review: diagnosis of Helicobacter pylori infection. Helicobacter. 2020;25(Suppl 1): e12735. https://doi.org/ 10.1111/hel.12735.

6. Yagi K, Nakamura A, Sekine A. Characteristic endoscopic and magnified endoscopic findings in the normal stomach without Helicobacter pylori infection. J Gastroenterol Hepatol. 2002;17(1):39-45. https://doi.org/10. 1046/j.1440-1746.2002.02665.x.

7. Yagi K, Aruga Y, Nakamura A, Sekine A. Regular arrangement of collecting venules (RAC): a characteristic endoscopic feature of Helicobacter pylorinegative normal stomach and its relationship with esophago-gastric adenocarcinoma. J Gastroenterol. 2005;40(5):443-52. https://doi.org/10. 1007/s00535-005-1605-0.

8. Nakayama Y, Horiuchi A, Kumagai T, Kubota S, Kobayashi M, Sano K, et al. Discrimination of normal gastric mucosa from Helicobacter pylori gastritis using standard endoscopes and a single observation site: studies in children and young adults. Helicobacter. 2004;9(2):95-9. https://doi.org/ 10.1111/j.1083-4389.2004.00204.x.

9. Anagnostopoulos GK, Yao K, Kaye P, Fogden E, Fortun P, Shonde A, et al. High-resolution magnification endoscopy can reliably identify normal gastric mucosa, Helicobacter pylori-associated gastritis, and gastric atrophy. Endoscopy. 2007;39(3):202-7. https://doi.org/10. 1055/s-2006-945056.

10. Machado RS, Viriato A, Kawakami E, Patricio FR. The regular arrangement of collecting venules pattern evaluated by standard endoscope and the absence of antrum nodularity are highly indicative of Helicobacter pylori uninfected gastric mucosa. Dig Liver Dis. 2008;40(1):68-72. https://doi. org/10.1016/j.dld.2007.08.003.

11. Gonen C, Simsek I, Sarioglu S, Akpinar H. Comparison of high resolution magnifying endoscopy and standard videoendoscopy for the diagnosis of Helicobacter pylori gastritis in routine clinical practice: a prospective study. Helicobacter. 2009;14(1):12-21. https://doi.org/10.1111/j.15235378.2009.00650.x.

12. Hidaka N, Nakayama Y, Horiuchi A, Kato S, Sano K. Endoscopic identification of Helicobacter pylori gastritis in children. Dig Endosc. 2010;22(2):904. https://doi.org/10.1111/j.1443-1661.2010.00943.x.
13. Cho JH, Chang YW, Jang JY, Shim JJ, Lee CK, Dong SH, et al. Close observation of gastric mucosal pattern by standard endoscopy can predict Helicobacter pylori infection status. J Gastroenterol Hepatol. 2013;28(2):279-84. https://doi.org/10.1111/jgh.12046.

14. Kato T, Yagi N, Kamada T, Shimbo T, Watanabe H, Ida K, et al. Diagnosis of Helicobacter pylori infection in gastric mucosa by endoscopic features: a multicenter prospective study. Dig Endosc. 2013;25(5):508-18. https:// doi.org/10.1111/den.12031.

15. Yan SL, Wu ST, Chen CH, Hung YH, Yang TH, Pang VS, et al. Mucosal patterns of Helicobacter pylori-related gastritis without atrophy in the gastric corpus using standard endoscopy. World J Gastroenterol. 2010;16(4):496500. https://doi.org/10.3748/wjg.v16.i4.496.

16. Tongtawee T, Kaewpitoon S, Kaewpitoon N, Dechsukhum C, Loyd RA, Matrakool L. Correlation between gastric mucosal morphologic patterns and histopathological severity of Helicobacter pylori associated gastritis using conventional narrow band imaging gastroscopy. Biomed Res Int. 2015;2015: 808505. https://doi.org/10.1155/2015/808505.

17. Garces-Duran R, Garcia-Rodriguez A, Cordova H, Cuatrecasas M, Gines A, Gonzalez-Suarez B, et al. Association between a regular arrangement of collecting venules and absence of Helicobacter pylori infection in a European population. Gastrointest Endosc. 2019;90(3):461-6. https://doi. org/10.1016/j.gie.2019.05.027.

18. Nakagawa S, Kato M, Shimizu Y, Nakagawa M, Yamamoto J, Luis PA, et al. Relationship between histopathologic gastritis and mucosal microvascularity: observations with magnifying endoscopy. Gastrointest Endosc. 2003;58(1):71-5. https://doi.org/10.1067/mge.2003.316.

19. Nomura S, Terao S, Adachi K, Kato T, Ida K, Watanabe H, et al. Endoscopic diagnosis of gastric mucosal activity and inflammation. Dig Endosc. 2013;25(2):136-46. https://doi.org/10.1111/j.1443-1661.2012.01357.x.

20. Dixon MF, Genta RM, Yardley JH, Correa P. Classification and grading of gastritis. The Updated Sydney System. International Workshop on the Histopathology of Gastritis, Houston 1994. Am J Surg Pathol. 1996; 20(10):1161-81. https://doi.org/10.1097/00000478-199610000-00001.

21. Lee JY, Kim N. Diagnosis of Helicobacter pylori by invasive test: histology. Ann Transl Med. 2015;3(1):10. https://doi.org/10.3978/j.issn.2305-5839. 2014.11.03.

22. Newcombe RG. Two-sided confidence intervals for the single proportion: comparison of seven methods. Stat Med. 1998;17(8):857-72. https://doi. org/10.1002/(sici)1097-0258(19980430)17.

23. Landis JR, Koch GG. The measurement of observer agreement for categorical data. Biometrics. 1977;33(1):159-74.

24. Li L, Jing J, Gao H, Zhang C, Lou H, Pan W. Regular arrangement of collecting venules under endoscopy for predicting a Helicobacter pylorinegative stomach: a systematic review and meta-analysis. Gastroenterol Hepatol. 2020. https://doi.org/10.1016/j.gastrohep.2020.08.003.

25. Yagi K, Nakamura A, Sekine A. Comparison between magnifying endoscopy and histological, culture and urease test findings from the gastric mucosa of the corpus. Endoscopy. 2002;34(5):376-81. https://doi.org/10. 1055/s-2002-25281.

26. Yagi K, Nakamura A, Sekine A. magnifying endoscopy of the gastric body: a comparison of the findings before and after eradication of helicobacter pylori. Dig Endosc. 2002;14(s1):S76-82. https://doi.org/10.1046/j.14431661.14.s1.10.x.

27. Hayashi S, Saeki S. Endoscopic microvascular architecture of the portal hypertensive gastric mucosa on narrow band imaging. Dig Endosc. 2007;19(3):116-23. https://doi.org/10.1111/j.1443-1661.2007.00701.x.

28. Genta RM, Lash RH. Helicobacter pylori-negative gastritis: seek, yet ye shall not always find. Am J Surg Pathol. 2010;34(8):e25-34. https://doi.org/ 10.1097/PAS.0b013e3181e51067.

29. Shiota S, Thrift AP, Green L, Shah R, Verstovsek G, Rugge M, et al. Clinical manifestations of helicobacter pylori-negative gastritis. Clin Gastroenterol Hepatol. 2017;15(7):1037-46. https://doi.org/10.1016/j.cgh.2017.01.006.

30. Nordenstedt H, Graham DY, Kramer JR, Rugge M, Verstovsek G, Fitzgerald $\mathrm{S}$, et al. Helicobacter pylori-negative gastritis: prevalence and risk factors. Am J Gastroenterol. 2013;108(1):65-71. https://doi.org/10.1038/ajg.2012. 372.

31. Yoshii S, Mabe K, Watano K, Ohno M, Matsumoto M, Ono S, et al. Validity of endoscopic features for the diagnosis of Helicobacter pylori infection status based on the Kyoto classification of gastritis. Dig Endosc. 2020;32(1):74-83. https://doi.org/10.1111/den.13486. 
32. Fukase K, Kato M, Kikuchi S, Inoue K, Uemura N, Okamoto S, et al. Effect of eradication of Helicobacter pylori on incidence of metachronous gastric carcinoma after endoscopic resection of early gastric cancer: an openlabel, randomised controlled trial. Lancet. 2008;372(9636):392-7. https:// doi.org/10.1016/S0140-6736(08)61159-9.

33. Raschke M, Lierse W, van Ackeren H. Microvascular architecture of the mucosa of the gastric corpus in man. Acta Anat (Basel). 1987;130(2):18590. https://doi.org/10.1159/000146443.

34. Gannon B, Browning J, O'Brien P, Rogers P. Mucosal microvascular architecture of the fundus and body of human stomach. Gastroenterology. 1984;86(5 Pt 1):866-75.

35. Gorczyca J, Litwin JA, Nowogrodzka-Zagorska M, Skawina A, Miodonski AJ. Architecture of blood vessels in human fetal gastric corpus: a corrosion casting study. Ann Anat. 1999;181(4):353-8. https://doi.org/10.1016/ S0940-9602(99)80127-7.

36. Gannon B, Browning J, O'Brien P. The microvascular architecture of the glandular mucosa of rat stomach. J Anat. 1982;135(Pt 4):667-83.

37. Lillibridge CB. The fine structure of normal human gastric mucosa. Gastroenterology. 1964;47:269-90.

38. Yuan C, Lin XM, Ou Y, Cheng Q, Cai L, Zhou P, et al. Gastric foveolar elongation causes invisibility of regular arrangement of collecting venules in chronic active and inactive gastritis. Helicobacter. 2021;26(1): e12770. https://doi.org/10.1111/hel.12770.

39. Kuznetsov K, Lambert R, Rey JF. Narrow-band imaging: potential and limitations. Endoscopy. 2006;38(1):76-81. https://doi.org/10. 1055/s-2005-921114.
40. Veijola L, Oksanen A, Linnala A, Sipponen P, Rautelin H. Persisting chronic gastritis and elevated Helicobacter pylori antibodies after successful eradication therapy. Helicobacter. 2007;12(6):605-8. https://doi.org/10. 1111/j.1523-5378.2007.00549.x.

41. Yao K, Iwashita A, Kikuchi Y, Yao T, Matsui T, Tanabe H, et al. Novel zoom endoscopy technique for visualizing the microvascular architecture in gastric mucosa. Clin Gastroenterol Hepatol. 2005;3(7 Suppl 1):S23-6. https://doi.org/10.1016/s1542-3565(05)00255-7.

42. Yao K. Gastric microvascular architecture as visualized by magnifying endoscopy: body and antral mucosa without pathologic change demonstrate two different patterns of microvascular architecture. Gastrointest Endosc. 2004; 59(4):596-7 (author reply 97). https://doi.org/10.1016/ s0016-5107(03)02825-6.

43. Saghier S, Schwarz SM, Anderson V, Gupta R, Heidarian A, Rabinowitz SS. Pediatric Helicobacter pylori gastropathy demonstrates a unique pattern of gastric foveolar hyperplasia. Helicobacter. 2018;23(3): e12487. https:// doi.org/10.1111/hel.12487.

44. Alaboudy A, Elbahrawy A, Matsumoto S, Galal GM, Chiba T. Regular arrangement of collecting venules: Does patient age affect its accuracy? World J Gastrointest Endosc. 2011;3(6):118-23. https://doi.org/10.4253/ wjge.v3.i6.118.

\section{Publisher's Note}

Springer Nature remains neutral with regard to jurisdictional claims in published maps and institutional affiliations.
Ready to submit your research? Choose BMC and benefit from:

- fast, convenient online submission

- thorough peer review by experienced researchers in your field

- rapid publication on acceptance

- support for research data, including large and complex data types

- gold Open Access which fosters wider collaboration and increased citations

- maximum visibility for your research: over 100M website views per year

At BMC, research is always in progress.

Learn more biomedcentral.com/submissions 